\title{
Solar Powered Rickshaw (SPR) can Diminish the Physical Labor of Rickshaw Puller and Improve the Power Crisis in Bangladesh
}

\author{
Md Meganur Rhaman ${ }^{1}$, Tanvir Ahmed Toshon ${ }^{2}$ \\ ${ }^{1}$ Assistant Professor, Department of Electrical and Electronic Engineering, Ahsanullah University of Science \\ and Technology, 141-142 Love Road, Tegjaon, Dhaka, Bangladesh \\ ${ }^{2}$ Tanvir Ahmed Toshon,19/4/B Monipuri Para, Tejgaon Dhaka-1215, Bangladesh
}

\begin{abstract}
Rickshaw is the most common three wheeler in Bangladesh. Easy availability, less fare, openness in structure etc. have made this very popular vehicle for short distance travel purposes. Two types of Rickshaws are seen plying on the road, one is manual peddling type another is an electric motorized type which needs to be charged using electricity from the national grid. Each type possess its own disadvantages. The first one need to be pulled by a man, which can be very hard \& laborious for the pullers. The second one needs electricity for charging purposes which is a burden on the national grid. In this paper, we tried to represent a new model of Rickshaw by mitigating the disadvantages of both types. The features, working mechanisms, structure, components etc. of the Solar Powered Rickshaw is discussed briefly with the necessary figures in this paper. The main objective of this paper is to relieve Rickshaw pullers from this kind of laborious job by using Solar Power Rickshaw (SPR) and help improving the power crisis in Bangladesh.
\end{abstract}

Index Terms: Solar Powered Rickshaw, Bangladesh, Motor, Controller, Battery, Solar Panel.

(C) 2014 Published by MECS Publisher. Selection and/or peer review under the responsibility of the Research Association of Modern Education and Computer Science.

\section{Introduction}

The word 'Rickshaw" originates from the Japanese word 'jinrikisha'. In Japanese language 'Jin"' means human, "Riki" mains power or force and "she" means vehicle. So, literally "jinrikisha" means human powered vehicle [1]. In Bangladesh Rickshaw differs from its original. Rickshaw has become a symbol of Bangladesh and especially for its design and arts. Dhaka is the capital city of Bangladesh is known as the world's capital city of rickshaws. There are no accurate figures or statics of Rickshaws that operates in the streets of Dhaka. Around 700,000- 800,000 Rickshaws are operating in Dhaka city now in the year 2012 and employ over one million people. Every day about 70 leeks or 7 million passenger trips are made in Dhaka by

Corresponding author. Tel.:

E-mail address: mizan_aust@yahoo.com, toshon.ndc@gmail.com 
Rickshaws over a distance of 11 million passenger miles. This is nearly twice the output of London's underground [2]. Still now in Bangladesh as a profession of Rickshaw driving is considered very low status work. Bangladeshi people call a Rickshaw driver as 'Ricshawala". The Rickshaw pullers are doing a very hard job, two or three persons sat down on Rickshaw under the hood and the driver pull or drive them by hands or feet. It is kind of barbarous and looks cruel when a Rickshaw puller works under strong sunlight with around $35^{\circ} \mathrm{C}$ temperatures.

The "Rickshaw" is a known vehicle around the world. It is a small scaled local means of vehicle. It is a human-pulled vehicle, usually contains two seats for carrying passengers and one driver seat. This nonmotorized form of public transport is a three wheeled vehicle capable of carrying two passengers excluding the driver, or a pay-load of 150-200 kg [3]. In Bangladesh roads are constrict and narrow in small towns, villages and even in the cities at residential areas. So Rickshaws are comfortable means of transport in Bangladesh. Increasing income level of lower middle class and middle class people has raised the number of Rickshaw passengers. People in Bangladesh tend to use Rickshaws for short distance travel purpose instead of walking. Rickshaws are widely used in almost all parts of Bangladesh. Still, in many parts of old Dhaka, Rickshaws are the only kind of vehicle that can travel through the narrow streets shown in Fig 1.

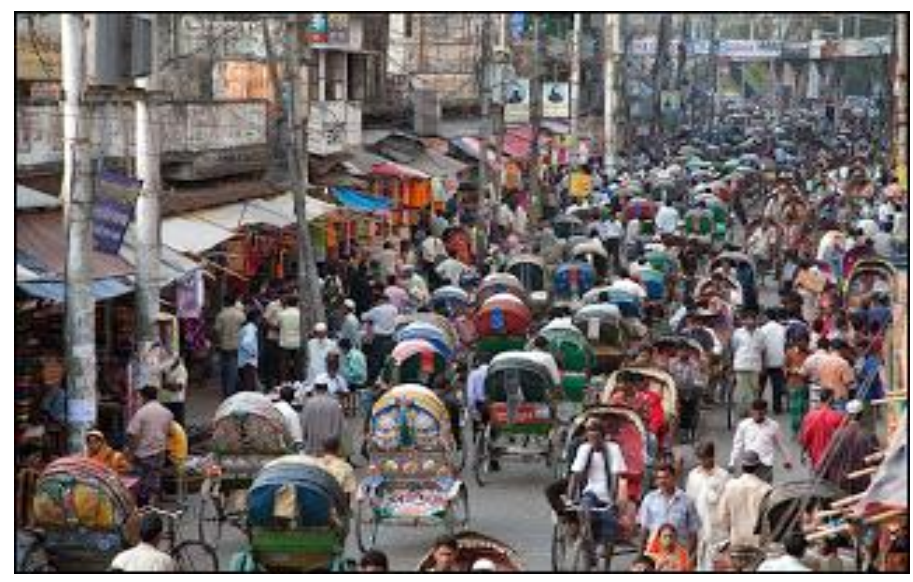

Fig 1. Rickshaw traffic in Old Dhaka, Bangladesh.

In Dhaka, most of the Rickshaw trips are kind of short with an average trip-length of $3.8 \mathrm{~km}$; the statistics indicates that in Dhaka nearly $40 \%$ of the loaded rickshaws are being used by women and children, or people carrying goods. Another $30 \%$ of users are students [4]. In addition, they are the only alternative in contrast to high cost taxi cabs, CNGs etc. And also to the poor service of public transports like minibuses and tempos. Rickshaws are much more feasible in these situations in-terms-of total travel-time and cost. In a city like Dhaka door-to-door mobility provided by Rickshaws is substantially important, especially for the vulnerable social groups - women, children and adults [5]. These are some reasons of the vast popularity of Rickshaw among major stratum of the society. It is also an important fact that most of the Rickshaw passengers belong from upper-middle to lower-middle income groups of the society.

At present around two million or twenty lakhs people earn their livings by means of Rickshaw in the country [6]. The majority of them are Rickshaw pullers, but there are also mysteries (repairers), owners, makers, shopkeepers (selling rickshaw parts, spare-parts and other materials), tea-stall owners and many others who survive on the basis of the rickshaw. The enormity of the Rickshaw sector has important impacts on the national economy. 34\% of the contribution of the transport sector to the GDP of Bangladesh comes from the Rickshaw sector [7]. If we consider for the fact that for every male employed there are at least three dependents, then nationally around six million or sixty lack people depend directly on the Rickshaws. 
Despite the advancement in last two decades, Bangladesh is still regarded as a less developed country. About 1.5 million people in the capital Dhaka are regarded as middle class and contribute vastly to the economic development. However, the decision-makers in the government are not much concerned about solving transport problems. Most of these people, neither possess their own vehicle nor do they get any transport facilities from their workplace. The public transport system is insufficient, because it doesn't provide transportation facilities in all areas of the city, especially remote areas. Taxicabs, CNGs and auto-rickshaws charge exorbitant fares and sometimes the drivers of such vehicles demands more money than the original meter cost per distance. Two decades back, Rickshaws plied most roads in the capital and ordinary people could travel to their desired destinations at affordable cost. The government has since made one road after another off-limits to Rickshaw, supposedly to ease traffic congestion, without arranging for any suitable alternatives for the people at large [8]. Manual Rickshaw driving is a laborious job, it looks kind of cruel, that one person is carrying two or three people at a time, shown in Fig 2.
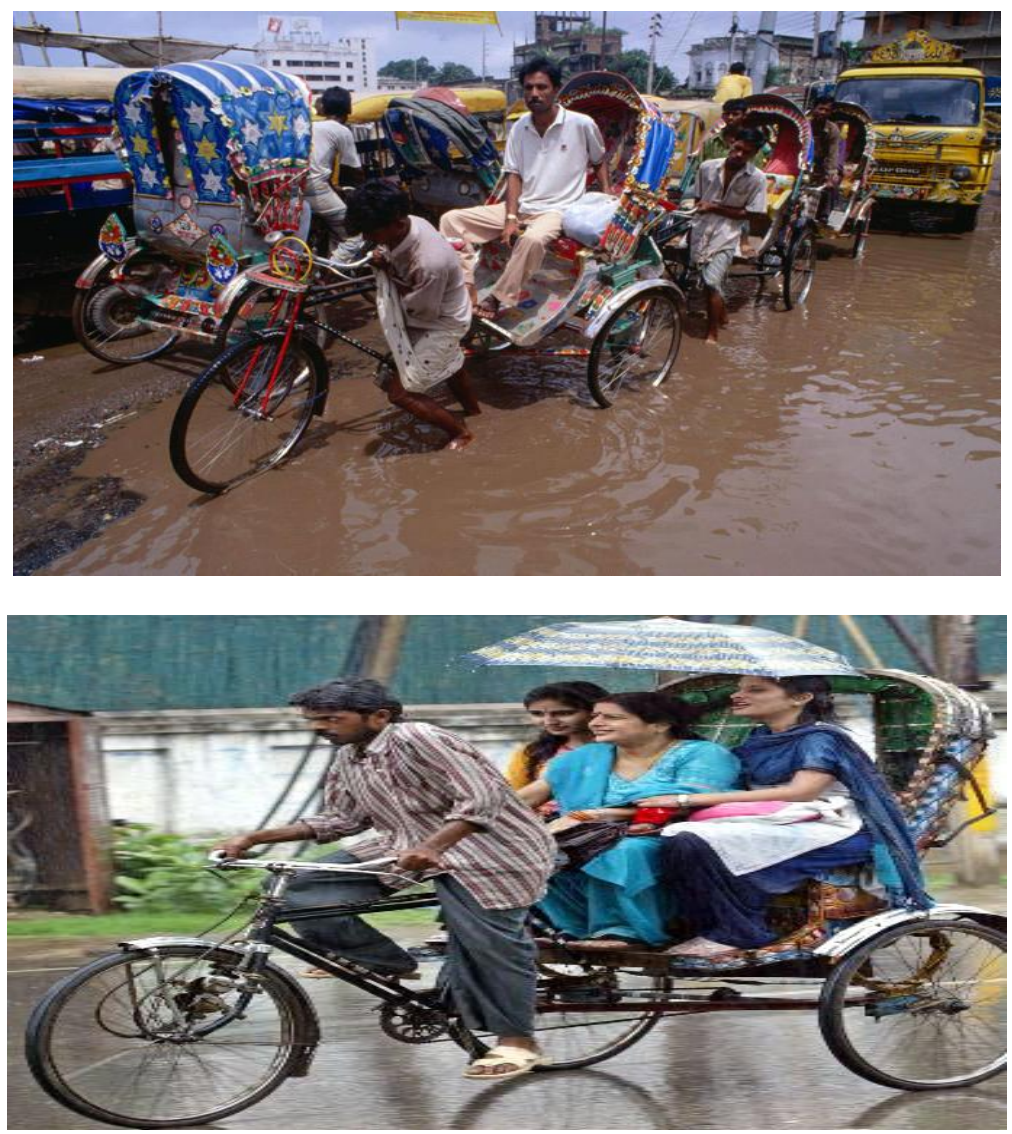

Fig 2. Hardships of Rickshaw Pullers.

Manual rickshaw can be driven only by young, full fit and strong people. Studies have shown that if a person continue to pull a rickshaw for 20-25 year continuously, he will surely face some orthopedic difficulties in his latter life. To overcome his kind of situation SPR can play vital roles. All people even disabled, older and women can drive the SPR as it does not need manual labor shown in Fig 3. 


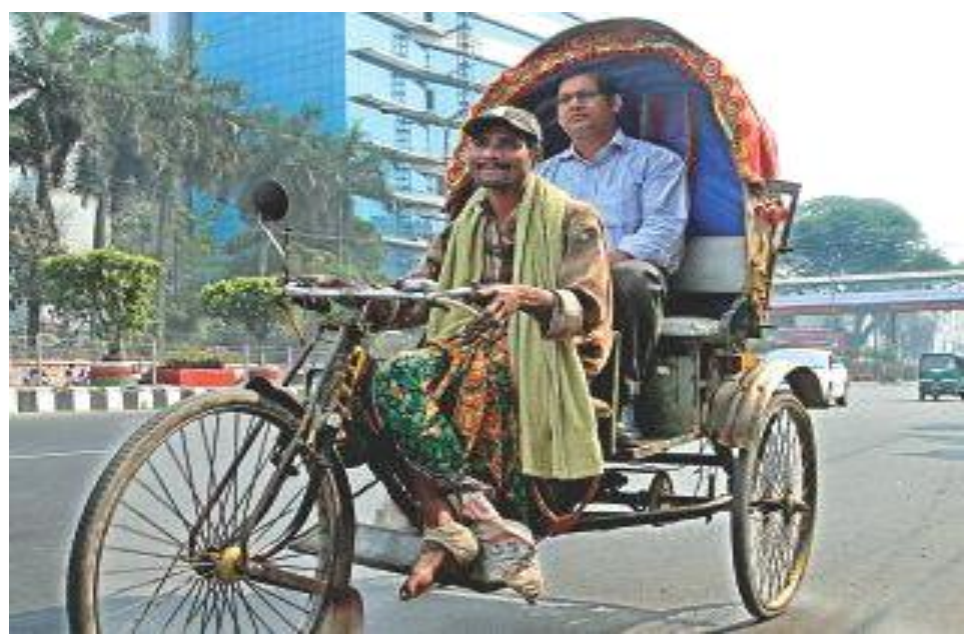

Fig 3. A disabled person is driving Motorized Rickshaw.

The price Solar Powered Rickshaw is about BDT 80000 (1 USD=79 Taka). A Rickshaw puller can nearly earn BDT 1,000 in a day [9]. Anyone can buy it on an installment payment basis so they can own it after finishing loan installments.

\subsection{Structural Development}

Beeva Tech Limited is the first professional Power Rickshaw manufacturer in Bangladesh. Their vision was eliminated manual labor of Rickshaw pullers and increase their daily income. Power Rickshaw is architecturally different from the traditional Rickshaws and is manufactured in a steel-body platform with state of wooden body, comfortable seat and large space, showing a 'new-look' Solar Power Rickshaw in Figure 4.

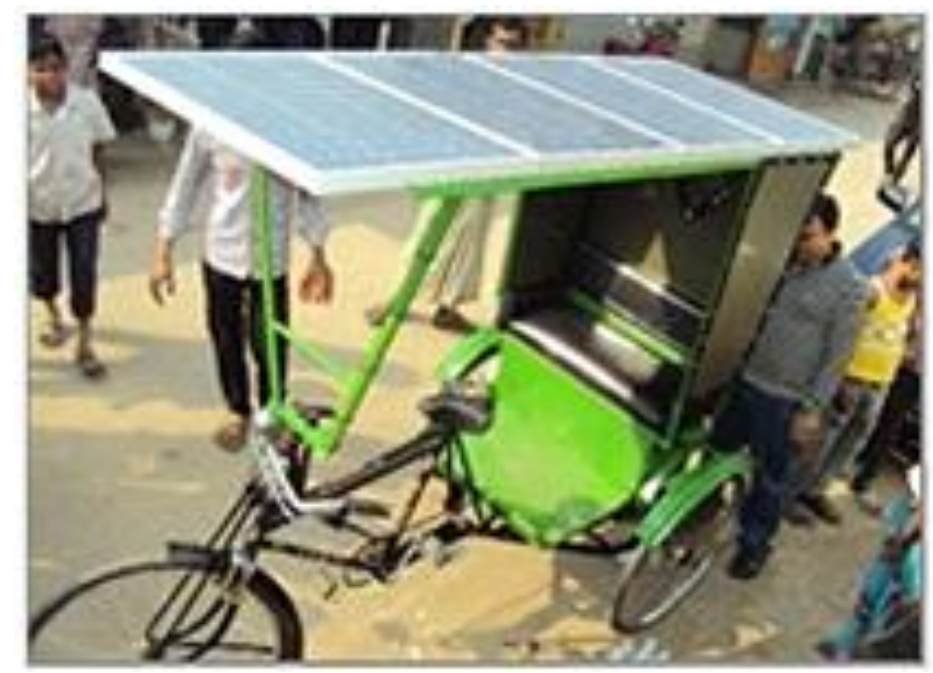

Fig 4. Structural view of Solar Powered Rickshaw. 


\section{Techniques}

The Government of Bangladesh banned import and assembly of an Electric Motorized Rickshaws because the Rickshaws are consuming $300 \mathrm{MW}$ power per day from the national grid [10]. Bangladesh is one of the most electric deprived countries. So, the government should encourage SPR and allow those to drive on all the streets of the capital and other municipality streets. It would help the lower middle class and poor people to have affordable means of transport. Beeva Tech Limited launched a newly designed Solar-Charged Electric Rickshaw for Bangladesh [11]. A 48V, 500W, 13.5A, 500 RPM rated Brushless DC (BLDC) gear motor is used in the system. The motor is mounted under the seat, attached to the main frame shown in Fig 5.

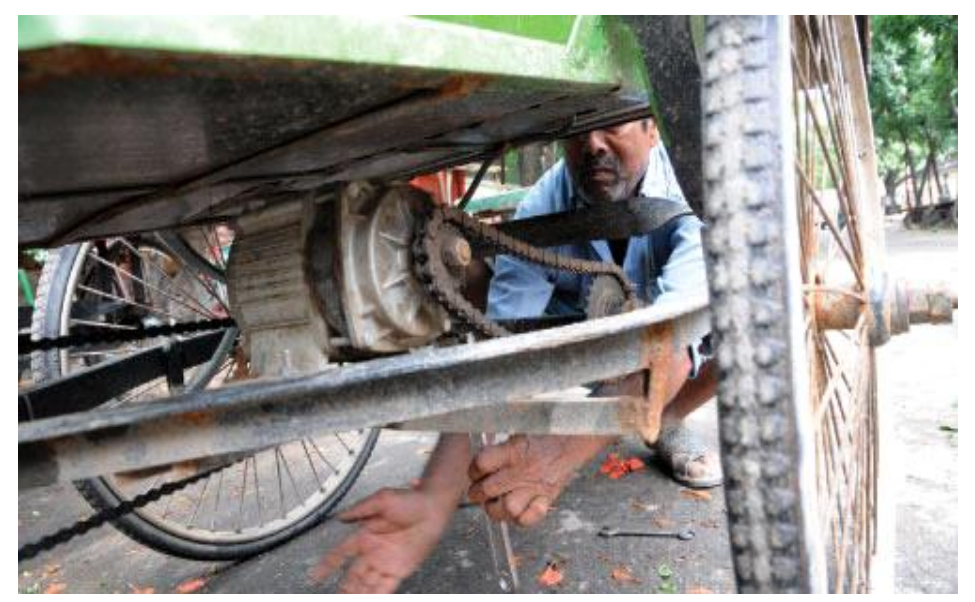

Fig 5. Electric motor installed beneath the frame of the vehicle.

Four $12 \mathrm{~V}, 20 \mathrm{Ah}$ rechargeable batteries were used in series to provide 48 Volts to the BLDC motor. These were lead-acid batteries each weighing $7.1 \mathrm{Kg}$ and 181 X 77 X $171 \mathrm{~mm}$ in dimension. The batteries were accommodated inside the seats shown in Fig 6.

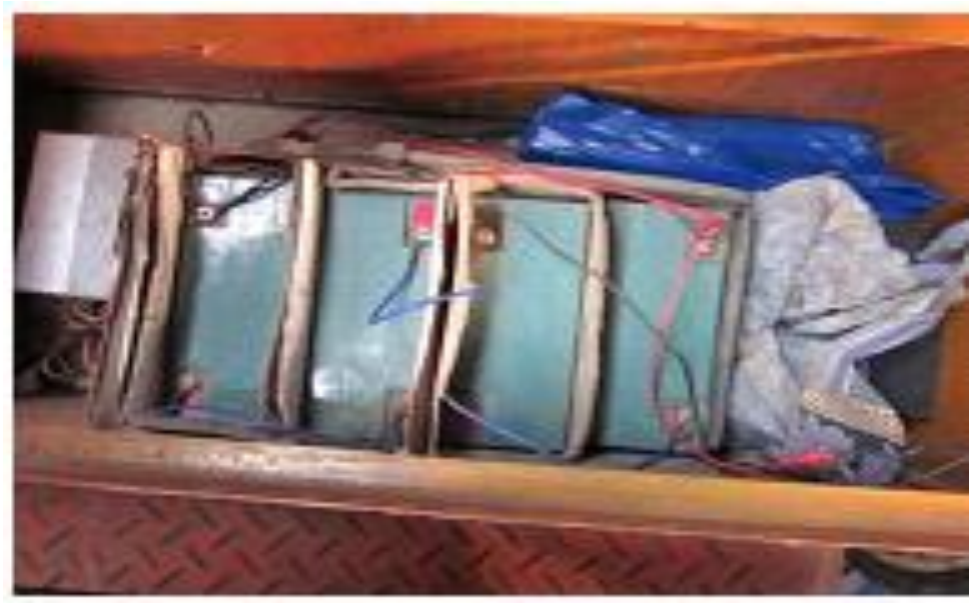

Fig 6. Batteries accommodated beneath the seat 
The controller is essential for BLDC motor because of complicated electronics connection and charger for charging battery shown in Fig 7.

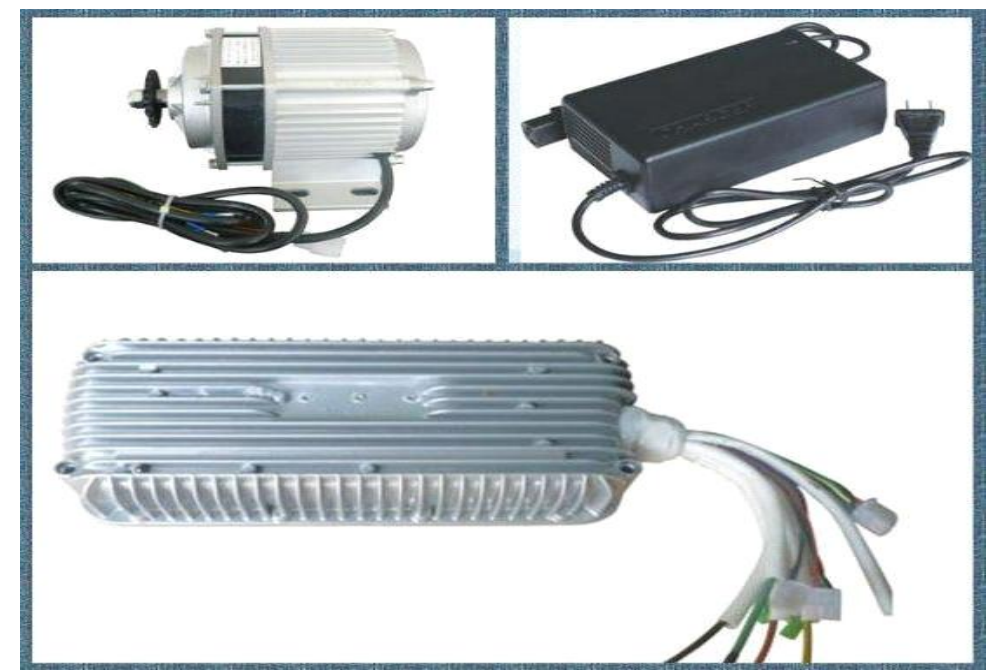

Fig 7. Electric brushless motor, controller and charger

A power key is used in the system to turn the whole system 'on' or 'off' manually. The hand-clutch is mounted on the left handle of the Rickshaw, along with the traditional front-wheel brake-system. It is used to stop the motor at-once when needed. The hand clutch will stop the motor irrespective of the throttle. It will start the motor from the corresponding throttle position shown in Fig 8.

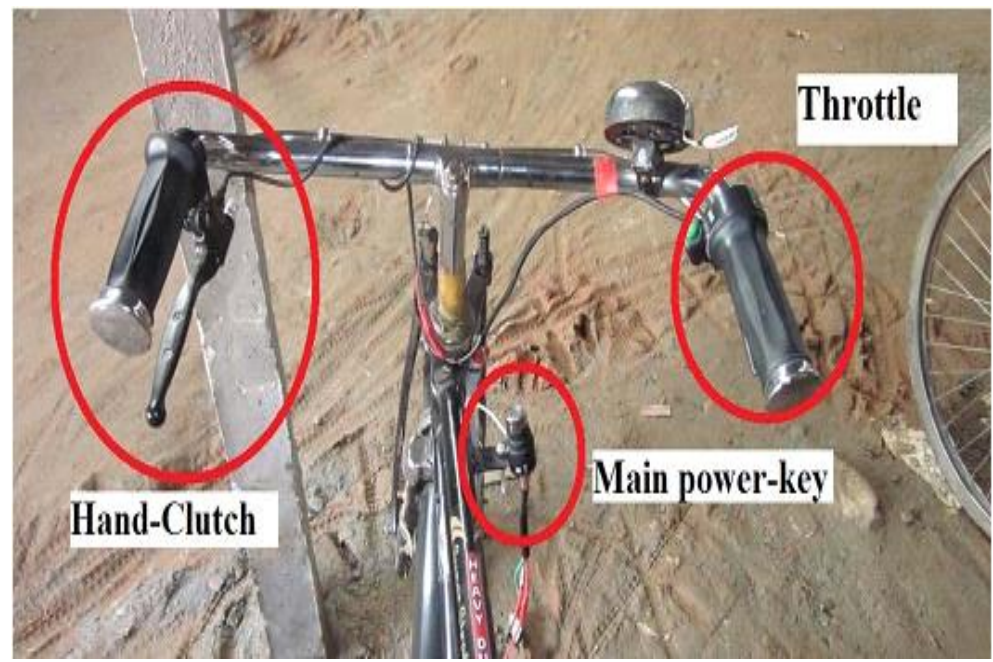

Fig 8. Position of the Hand-Clutch, Power-key, and Throttle.

Fig 9 shows the connections of the motor wires with the controller, Throttle Position Sensor (TPS), and Power-key. The hall-sensors of the BLDC motors and the motor phase cables are also connected in the diagram. 


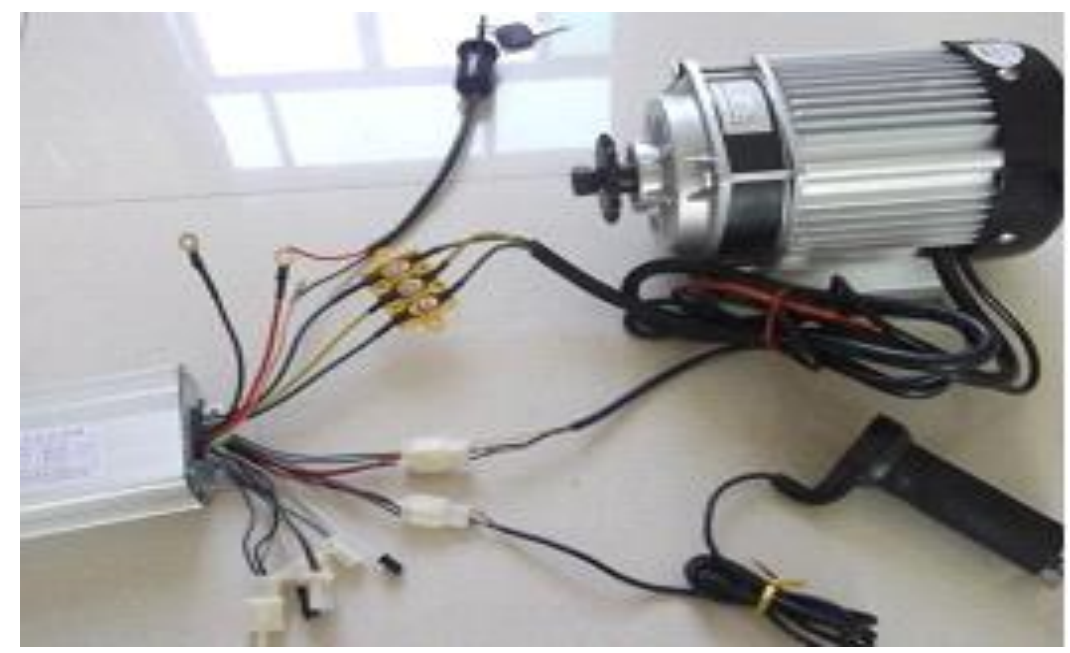

Fig 9. Electric components assembled separately

We have developed some unique models for Solar Power Rickshaw. They are mentioned below:

\subsection{Solar + Electric Charging System}

Four $75 \mathrm{~W}$ solar panels over the rickshaw ceiling for battery charging shown in Fig 4. It was proved that the panels were insufficient for charging the batteries to run the $500 \mathrm{~W}$ motor for a long time. To solve this problem, it is necessary to charge the batteries using electricity from the national grid, so a parallel charging mechanism is used for additional charging purpose excluded from the panel charging system. This hybrid 'green' rickshaw can play around 10 hours [9].

\subsection{Solar + Pedal System}

'Soleckshaw' - a rickshaw powered by solar electric power which was inaugurated in October, 2008 has been launched as a green postal delivery vehicle in India [12] shown in Fig 10. Soleckshaw is battery-powered and pedal assisted dual powered tricycle. Besides pedaling, Soleckshaw will provide some battery support on demand. The batteries are charged at charging stations which are solar powered. It doesn't possess any solar panels on the ceiling for charging purposes. The Soleckshaw utilizes a battery exchange design that uses solar battery recharging stations. This design eliminates the needs to place the solar panels on the ceiling of the vehicle, thus reducing weight and cost [13]. The Soleckshaw's technical design involves a 240-350 W brushless DC motor [14]. It consists a seating capacity of 2-3 passengers and a payload of 150-200 kg, excluding the driver, and can be driven at a speed of $15 \mathrm{~km}$ per hour with full load. It can be driven up to 40 $\mathrm{km} / \mathrm{hr}[15]$. 


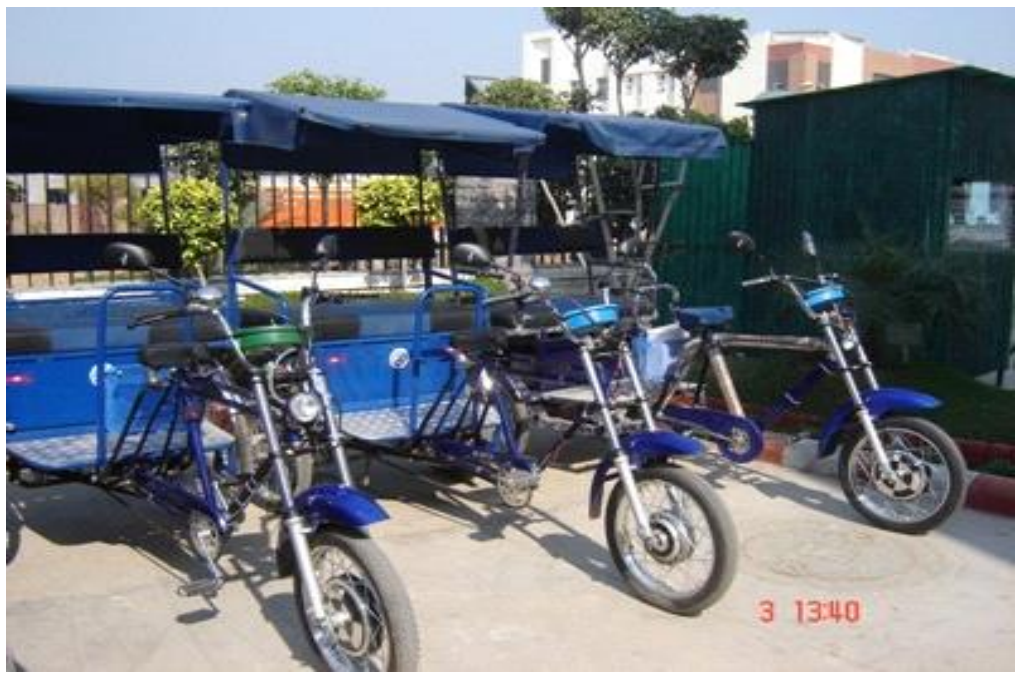

Fig 10. Solar Powered and Pedal assisted Rickshaw

It includes a high initial cost. As this design indicates that it is also throttle controlled, practically and it takes 6-7 hours to discharge the battery [20] and requires a full day for the full charging purpose. Rickshaws shaft speed corresponds to manual pedaling and motor RPM. In Fig 11 it is shown that the motor is running but the total shaft speed is tending to follow the pedal speed as it is higher for a variation of 2.2 to 2.8 Volts. After the breakeven point of $2.8 \mathrm{~V}$, the shaft speed follows the motor speed [16].

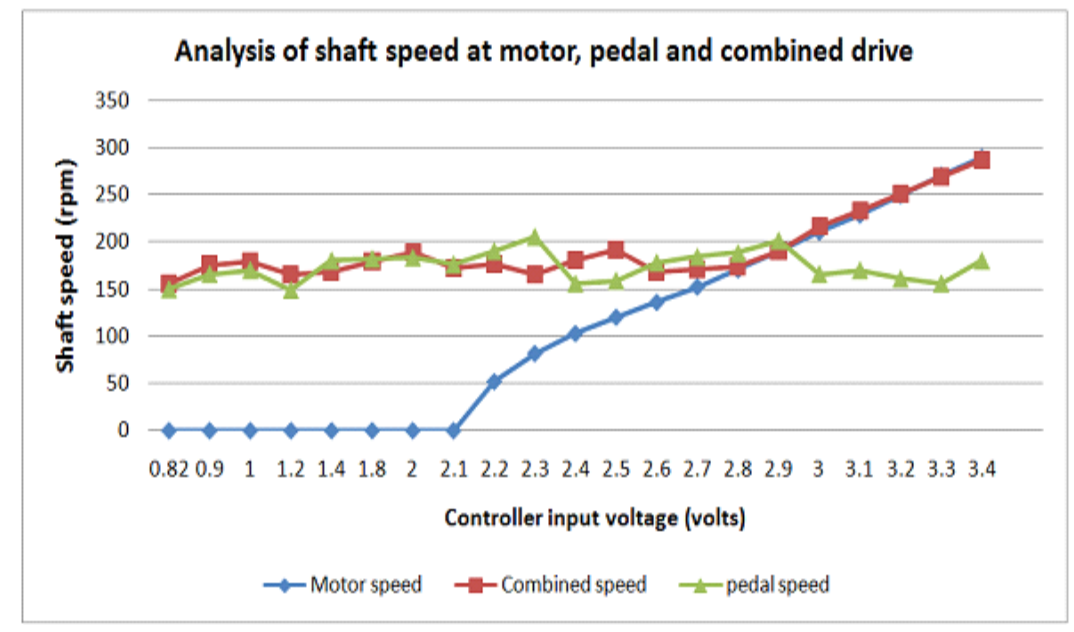

Fig 11. Analysis of resultant speed at combining forces.

\subsection{Solar Power Rickshaw without Panel}

There should be a battery-swapping process rather than using solar-panels attached over the vehicle. It will reduce cost and weight. The battery swapping process should be efficient and a role model for the next 
generation sustainable refueling infrastructure. For this type of Rickshaw, it is essential to establish a "Central Solar Battery Charging Station” (CSBCS) shown in Fig 12.

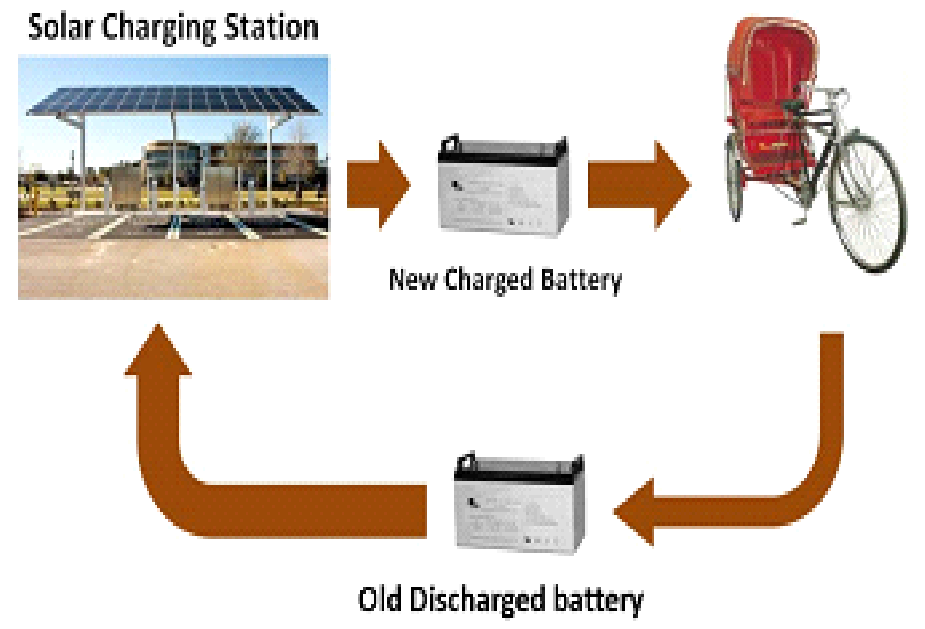

Fig 12. CSBCS, Power Rickshaw and Battery.

\section{Discussion}

Solar Power Rickshaw diminishes the physical labor of the rickshaw puller. We should consider how these Rickshaw drivers contributing to our rural economy and keeping the environment carbon free in some degrees. Also, it will save a huge amount of electricity, 300MW which is taken by Electric Power Rickshaw from the national grid. It will be flexible means of transport for passengers as it gives them extra comfort for seat and space and would reach their destinations faster compared to the existing Manually-Paddled Rickshaw with more or less same fare. The SPR can run at $25 \mathrm{~km}$ per hour. The SPR has a longer battery life time because of infrequent charging. SPRs are faster than conventional Rickshaws, needless human effort to be plied on the street. From the types of SPR mentioned earlier in the paper, the latter one is the most economical \& feasible for practical use. Solar Power is absolutely dependent on the availability of sunlight, so in case of rainy and foggy day, when the sun isn't visible, it will not be able to work properly. For these special circumstances the CSBCS can arrange an alternative Electric Charging System (Grid Line/Generator) to charge the batteries if necessary.

\section{References}

[1] http://weloveourbangladesh.blogspot.com/2012/08/rickshaws-of-bangladesh-and-its history_7522.html.

[2] www.dhakacalling.com/archive/2013/april/cover_story.php.

[3] S. Gadepalli, "Rickshaws in the new millennium", The Daily Star, June 30 2006, from http://www.thedailystar.net/2006/06/30/d606300901105.htm.

[4] Strategic Transport Plan, "Strategic Transport Plan for Dhaka- Final Report", Dhaka Transport Coordination Board, Dhaka, Bangladesh, 2005.

[5] S. Rahman, "Future mass rapid transit in Dhaka city: Options, issues and realities", Jahangirnagar Planning Review, vol. 6, pp. 69-81, 2008. 
[6] M. Ali and R.Islam, "Livelihood status of the rickshaw pullers", The Good Earth, Dhaka, 2005.

[7] J. Whitelegg, and N. Williams, "Non-motorized transport and sustainable development: Evidence from Calcutta", 2005. Retrieved July 28, 2009, from http://www.ecologica.co.uk/pdf/Calcutta2.pdf.

[8] Md Ashraf Hossain, " Encourage motorised rickshaw", Daily New Age, June 4 2012, from http://newagebd.com/detail.php?date=2012-06-04\&nid=12530\#.UkNZwifFmQI.

[9] "Rickshaws that run on solar power", The Daily Star, January 26, 2012, from http:// archive .thedailystar.net/newDesign/ news-details.php?nid=219899.

[10] Tawfique Ali, "Electric Rickshaws run out of steam", The Daily Star, May 30 2011, from http://archive.thedailystar.net/newDesign/news-details.php?nid=187825.

[11] http://beevatech.com/product_Gallery.php.

[12] SriramVadlamani, "Soleckshaw - Solar rickshaw as green postal delivery vehicle!’Jul 10, 0 10:10PM UTC, Available at: http://asiancorrespondent.com/37308/soleckshaw-2\%80\%93-solar-rickshaw-as-greenpostal-delivery-vehicle/.

[13] Web: http://www.lendenton.com/soleckshaw-technology-brief/, retrieved, 2 September, 2012.

[14] Official website: Department of Science and technology, India http://www.dst.gov.in/whats_new/pressrelease08/solekshwa-launched.htm.

[15] Power Point Presentationon Seminar on Contemporary Issues In Management; Presented by: Dipal Sukhadiya, issue 1: Energy Management available: http://www.scribd.com/doc/38994039/soleckshaw09 mba57.

[16] Huq, Rachaen Mahfuz, "Development of Torque Sensor Based Electrically Assisted Hybrid Rickshaw", 4 September, 2012, Available at: http://dspace.bracu.ac.bd/handle/10361/2122.

\section{Authors' profiles}

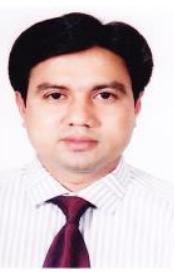

Md Meganur Rhaman is an Assistant Professor in the department of Electrical and Electronic Engineering (EEE) at Ahsanullah University of Science and Technology (AUST), Dhaka from October 2005.He has completed his BSc in EEE from AUST in 2004. He has completed his M.Engg in EEE from Bangladesh University of Engineering and Technology (BUET) in 2010 and study PhD at BUET. Right now he teaches the courses on Electronic, Biomedical Engineering, Measurement and Instrumentation, Basic Electrical Circuits and Control System. He has several publications in Biomedical Engineering and

Renewable Energy.

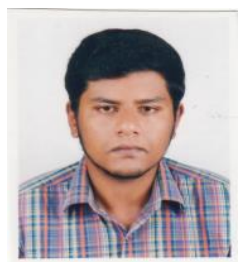

Tanvir Ahmed Toshon is an Electrical \& Electronics Engineering Graduate from Ahsanullah University of Science \& Technology, Dhaka, Bangladesh. This paper is written on the basis of his undergraduate research project "Solar based transportation system in Bangladesh". He has been involved with a lot of projects related to power system \& renewable energy during his undergrad. Currently he is looking forward to pursuing a $\mathrm{PhD}$ program in USA.

How to cite this paper: Meganur Rhaman, Tanvir Ahmed Toshon,"Solar Powered Rickshaw (SPR) can Diminish the Physical Labor of Rickshaw Puller and Improve the Power Crisis in Bangladesh", IJEM, vol.4, no.4, pp.26-35, 2014.DOI: 10.5815/ijem.2014.04.03 